\title{
MANOEL BOMFIM E A IDEOLOGIA DO IMPERIALISMO NA AMÉRICA LATINA
}

\author{
José Maria de Oliveira Silva \\ Departamento de Ciências Sociais - UFS
}

RESUMO: Este artigo discute divergências entre intelectuais brasileiros sobre a política norte-americana para a América Latina a partir das críticas de Manoel Bomfim ao imperialismo norte-americano e europeu. Analisa sua concepção sobre a Doutrina Monroe e a idéia de solidariedade entre os países latino-americanos como fator de resistência.

ABSTRACT: This article examines the divergences among Brazilian intelectuals about American foreign policy for Latin America considering Manoel Bomfim's criticism against American and European imperialism. It discusses his conception of the Monroe Doctrine and of the Latin American countries' solidarity as a factor of resistance.

PALAVRAS-CHAVE: Imperialismo, Nacionalismo, América Latina, Manoel Bomfim, Doutrina Monroe

KEYWORDS: Imperialism, Nationalism, Latin America, Manoel Bomfim, Monroe Doctrine

Na primeira parte de sua obra sobre a América Latina (1905) - "A Europa e a América Latina" - o escritor sergipano se referia criticamente às representações ideológicas comuns na imprensa européia sobre as Repúblicas latino-americanas. Elas eram vis-

\begin{abstract}
Nós outros, argentinos, peruanos, brasileiros, chilenos - que somos dos chamados latino americanos nunca pensamos em América Latina (BOMFIM. O Brasil na América, 1929, p. 11).
\end{abstract}

tas pelos governos, economistas, sociólogos e jornalistas europeus como localidades com muitas riquezas, um continente extenso, mas que estavam sujeitas à uma política de crises violentas, lutas armadas, com um povo rebelde e ingovernável e estadistas desonestos. 
Apoiando-se numa visão racista e, ao mesmo tempo, ameaçadora, a ideologia imperialista afirmava ser inconcebível que "milhões de preguiçosos, mestiços degenerados, bulhentos e bárbaros se digam senhores de imensos e ricos territórios" enquanto que a Europa 'rica', 'sábia', e 'civilizada' se comprimia em pequenos territórios" (BOMFIM, 1905, p.1-4).

Manoel Bomfim era natural de Aracaju (1868). Após realizar seus estudos iniciais na sua terra natal, ingressa na Faculdade de Medicina da Bahia, transferindo-se daí para curso semelhante no Rio Janeiro. Participante das lutas políticas de sua época desde estudante, colabora no Correio do Povo, dirigido pelo seu amigo Alcindo Guanabara. Como intelectual, adota postura radical no enfrentamento de questões candentes nos inícios da República, sobretudo, com a crítica ao racismo (e seus desdobramentos, entre os quais, o imperialismo) e em defesa da educação popular. Questões que serão retomadas nas suas diversas obras sobre assuntos educacionais, e, sob viés nacionalista, na trilogia publicada nos anos vinte, O Brasil na América, O Brasil na História, O Brasil Nação.

Para Bomfim, a condenação do povo latino-americano tinha uma dupla causa: uma causa intelectual, fruto do desconhecimento da realidade latino-americana, de sua história, do seu passado colonial; e uma causa interesseira visando a conquista do território. A imagem das repúblicas latino-americanas se assemelhava a do estudante "indisciplinado e relapso", à quem o mestre escola chamava constantemente atenção:

Se você me ouvisse, se não fosse um malandro, faria isto e mais isto e isto (...) mas você não presta para nada (...) . Nunca fará nada! Nunca saberá Nada! Nunca será nada! (BOMFIM, 1905, p.2-3).

Embora o primeiro aspecto, a causa intelectual, não fosse evidente, pois o autor desconhecia a grande curiosidade e as contribuições de naturalistas, viajantes e exploradores estrangeiros do século passado, as imagens reafirmavam a ideologia do colonizador: os que nasciam na América continuavam a ser vistos como inferiores racial e culturalmente.

No contexto de uma afirmação de uma identidade continental, a linguagem americanista de Manoel Bomfim em muito se assemelhava a de José Martí contra a opiniões do jornal The Manufaturer que, nesse período, retratava os cubanos, estabelecidos na América do Norte, como um "povo de vagabundos míseros ou pigmeus imorais", "inúteis verbosos", incapazes de ação", "povo efeminado" (MARTI, apud RETAMAR, 1985, p.52-57).

O livro do escritor sergipano, publicado em 1905, A América Latina, ao contestar a visão pessimista e os preconceitos racistas sobre o Povo e a Nação americanos aparecia aos olhos de nacionalistas brasileiros como "uma resposta ao conceito do estrangeiro sobre nós" (VICTOR, 1905, p.610-612). Incentivado pelo ideal do movimento jacobino "A América para os americanos", que aparecia como epígrafe do jornal desse agrupamento político no Rio de Janeiro, o debate sobre o imperialismo dividia as opiniões de republicanos, monarquistas, liberais, socialistas, anarquistas, que muitas vezes, manifestavam opiniões idênticas sobre a Doutrina Monroe, o Panamericanismo e os monopólios estrangeiros. Havia um certo silêncio, entretanto, segundo Bomfim, entre intelectuais e políticos nacionalistas com relação às possibilidades de unidade entre os povos da América Latina.

Segundo Leroy Beaulieu, um dos primeiros a teorizar sobre as noções de colônias de povoamento e colônias de exploração que serviu de modelo para várias interpretações sobre os diferentes sistemas coloniais (NOVAIS, 1977, p.12-13) e defensor do neo-colonialismo francês na África, o perigo para a América Latina não estava na possibilidade de uma conquista européia, mas era representado pelo crescimento da imigração e capitais da América do Norte. Para enfrentar essa ameaça, os países latino-americanos deveriam manter a ordem interna (uma vez que a instabilidade democrática era freqüente), a paz en- 
tre todas as Repúblicas, aprofundando os relacionamentos comerciais e financeiros com a Europa (LEROY-BEAULIEU, 1902, p.305-306)

Por outro lado, o Brasil, durante todo o século XIX, não participara dos vários Congressos sobre a unidade da América Latina. Algumas explicações tradicionais sobre esse isolamento assinalam que era devido à forma monárquica do regime, às diferenças da língua, às ligações da família real com a Áustria, aos problemas de limites e à escravidão. Para alguns historiadores, fatores geográficos ou étnicos tinham afastado a possibilidade de uma política de unificação do Continente (NORMANO, s.d., p.148-149). Uma das tentativas em que se discutiu o processo de unificação no século passado deu-se por iniciativa de liberais chilenos, quando foi criado a União Americana, logo após a intervenção francesa no México (25 de maio de 1862). O objetivo inicial era organizar sociedades patriotas nos vários países hispano-americanos, divulgar o processo de independência através de correspondências, ensaios e outros documentos e lutar pela união desses Estados. Estabelecendo-se por meio de uma Junta, além do Chile, outras instituições similares surgiram na Bolívia, Peru, México.

Para o autor da América Latina a política externa brasileira durante o Império tinha sido anti-americana e imperialista. Nesse sentido, crítica o imperialismo brasileiro com o envolvimento na Guerra contra o Paraguai como um "crime" contra o povo americano (BOMFIM, 1931, p.305, v.1). No entanto, com a emergência de tantas guerras, envolvendo os países do Continente, não era um contra-senso pensar na possibilidade das nações americanas viverem como "irmãs"? O "inimigo" externo parecia a vários intelectuais desses países que estava mais próximo, nas fronteiras, e não na Europa. Uma visão que Eduardo Prado, escrevendo nessa época (1893), explora quando afirma que a fraternidade americana era uma "mentira", em função das "lutas" e dos conflitos entre estas nações:
O México deprime, oprime e tem por vezes, invadido a Guatemala, que tem sangrentíssimas guerras com a república do Salvador, inimiga rancorosa de Nicarágua, feroz, adversária de Honduras, que não morre de amores pela República de Costa Rica (...). A Colômbia e a Venezuela odeiam-se de morte. O Equador é a vítima, nunca resignada, ora das violências colombianas, ora das pretensões do Peru. E o Peru? Já não assaltou a Bolívia, já não se uniu depois a ela numa guerra injustíssima ao Chile? E o Chile, já não invadiu duas vezes a Bolívia e o Peru, não fez um horroroso morticínio de bolivianos e peruanos na última guerra, talvez a mais sangrenta deste século? E o Chile, não tem somente estes inimigos: o seu grande adversário é a República Argentina (PRADO, 1980, p.18-19).

Não era de se estranhar, portanto, que as elites políticas brasileiras e mesmo alguns intelectuais de tendências socialistas como Lima Barreto e Euclides da Cunha se sentissem "envergonhados" quando o Brasil era comparado no estrangeiro com uma "República dos Caudilhos" da América hispânica (SEVCENKO,1985, p.45). O primeiro, redigindo um rascunho de carta a Rui Barbosa em 25 de agosto de 1909, afirmava:

Queira, Senhor Conselheiro Rui Barbosa, aceitar os meus parabéns e o voto ardente que faço pela vitória do seu nome nas urnas.

É em nome da liberdade, da cultura e da tolerância, que um "rôto" como eu, se anima a lhe declarar tão grandes sentimentos de suas ambições políticas, que consistem simplesmente em não desejar para o Brasil o regímen do Haiti, governado sempre por manipansos de farda, cujo culto exige sangue e violência de tôda a ordem, Isaías Caminha (BARRETO, 1961, p.194)

A solidariedade sul-americana aparecia como um sonho irrealizável e "perigoso". Como o Brasil, perguntava o próprio Euclides da Cunha, poderia se alinhar com países mergulhados em conflitos e revoltas, sem perspectivas de progresso, como era o caso do Paraguai "convalescente", da Bolívia "dilacerada pelos motins e pelas guerras", ou ainda com o Uruguai e com o Peru? (CUNHA, 1975, p.109). A solidariedade Continental, à qual Bomfim ingenuamente reconhecia 
como sendo um dos fatores de resistência à qualquer invasão estrangeira, era anulada não só pelos conflitos bélicos entre esses países e pressões das grandes potências, mas também por uma visão cultural homogeneizadora que expressava sentimentos questionadores sobre a solidariedade entre os latino-americanos.

Desde meados do século passado, os movimentos de unidade americana não obtém sucesso a nível governamental. A Argentina, que vangloriava-se de possuir cerca da metade dos recursos econômicos da América do Sul e "sentir-se européia e não americana", aproximava-se cada vez mais dos países europeus (sobretudo da França, Espanha, Itália, Alemanha), ao mesmo tempo em que, incentivada pelos investimentos ingleses, não pensava numa política de unidade com os outros países sul-americanos, mas na hegemonia sobre o Continente (NORMANO, s.d., p.154). Alguns escritores argentinos, bastante conhecidos, como Alejandro E. Bunge e José Ingenieros, defendiam a liderança de seu país frente à seus dois rivais, o Brasil e o Chile, com argumentos de que o clima e a raça eram empecilhos ao primeiro, e, o pequeno território e os interesses voltados para o Pacífico impediam a hegemonia chilena no Continente.

Ao publicar as estatísticas sobre o crescimento argentino para o ano de 1906, o jornal La Prensa destacava argumentos sobre a superioridade nacional. Contrapondo-se ao maior território do Brasil, afirmava que este fator era compensado "...pela terra mais rica dos Pampas, pelo clima argentino mais salubre, por um número maior de imigrantes europeus e um índice mais rápido de desenvolvimento econômico da área do Prata". Além disso, a Argentina possuía "mais estradas de ferro, mais linhas telegráficas, mais navios de guerra e mais comércio do que o seu maior vizinho" (BURNS, 1978, p.390).

Dois anos antes, sentimentos idênticos tinham sido expressos pelo presidente Theodore Roosevelt com objetivos de melhorar as relações com a Argentina. Ela era na sua visão a "Nação eleita" devido ao seu progresso e a sua raça para garantir a Doutrina Monroe na América do Sul (BANDEIRA, 1978, p.171). Nos Congressos pan-americanos a imagem da "ameaça" aos países do sul era substituída pela linguagem diplomática de Washington, que por meio de tratados e promessas enfatizavam os compromissos da Doutrina Monroe e o espírito pan-americano de "ideais comuns e aspirações comuns" (LIMA, 1971, p.517; 1953).

Na primeira Conferência Pan-americana, realizada em Washington sob a presidência de Blaine, o Chile não quis participar temendo discussão sobre os incidentes com o Peru. Até 1899, data do primeiro congresso pan-americano, os Estados Unidos já tinham transformado Porto Rico numa colônia, tomado posse da região do Caribe, Cuba tinha ficado sujeita ao direito de intervenção nos seus assuntos. Além disso, através do Tratado de Hay-Pauncefote os Estados Unidos asseguraram o direito a um canal através do istmo, motivando a "revolução local" e a separação do Panamá na Colômbia. No outro extremo, os americanos expandiam seus interesses para a região do Oriente. Anexavam as Ilhas do Havaí, as Filipinas, enviando ainda tropas para ajudar as legações de Pequim na guerra dos boxers.

Para "assegurar a paz no hemisfério ocidental", como falava Theodore Roosevelt, os Estados Unidos desde a guerra com a Espanha até os anos de 1903/ 1904 desenvolveram uma política agressiva quanto a América Latina (PERKINS, 1964; PEREYRA, 1969). Com o conflito Venezuelano, que serve a BOMFIM como ponto de partida para o seu questionamento sobre a Doutrina Monroe, o governo americano estabeleceu um Novo Corolário aos princípios de 1823 e tornava pública a política do big-stick. Nela vinha expressa uma nova postura com relação aos países americanos: as nações que cumpriam com suas obrigações e compromissos políticos e sociais nada teriam a temer de uma possível interferência norte-americana. As que tinham um "mau procedimento", governos desonestos, poderiam forçar os Estados Unidos 
a intervirem. Com isso, atribuía-se à nação americana o papel de polícia de todo o hemisfério ocidental (LEUCHTENBERG, 1976, p.158; BELLOTO e CORRÊA, 1979).

Reservando-se o direito de intervenção nos países latino-americanos, em função de sua "anarquia" social e política, o Corolário Roosevelt fez crescer os temores de uma possível invasão do Continente. Quando aplicado pela primeira vez em 1905 na República Dominicana o big stick, obrigou o governo local a assinar com os Estados Unidos um protocolo em que responsabilizar-se-ia pela coleta dos direitos aduaneiros e pagamentos dos credores, mantendo $45 \%$ para as despesas com a administração pública.

As várias ações anteriores de desembarque de tropas para a proteção dos interesses norte-americanos na Nicarágua $(1894,1896,1898)$, no Panamá $(1895,1903)$, em Cuba (1898), Colômbia (1902), Honduras (1903), e a tomada de Porto Rico (1898), Nicarágua (1900), Costa Rica (1900), e a imposição da Emenda Platt, permitindo a intervenção armada em Cuba (1902), evidenciavam ainda mais aqueles temores (SODRÉ, 1987).

De um modo geral, eram poucos os escritores e políticos brasileiros que criticavam os avanços do imperialismo norte-americano naqueles países. Em 1894 o governo brasileiro erguia no Rio de Janeiro um monumento a James Monroe e apreendia o livro de Eduardo Prado, A Ilusão Americana. Tais fatos ampliam a polêmica sobre a Doutrina Monroe. Nacionalista, contrário às aproximações do governo de Floriano Peixoto com os Estados Unidos, Eduardo Prado, numa imagem ímpar sobre o pan-americanismo de Blaine (Ministro das Relações Exteriores), desnudava os interesses daquela ideologia:

Ele (Blaine, J.M.) imaginava a águia americana pairando de polo a polo, com as asas poderosas expandidas. A águia simbólica ele não via protegendo os fracos com a sua sombra, como acredita a ingenuidade de alguns sul-americanos. Ele queria que ela dominasse, que o seu olhar perscrutasse as solidões geladas do pólo, os vales profundos dos Andes, as planuras do amazonas, a vastidão dos pampas e o infinito dos mares. Ele queria que o bico adunco daquele pássaro apocalíptico rasgasse os inimigos, e que as garras colossais se apoderassem de todo o continente de Colombo. Blaine no poder, era uma ameaça para toda a América (PRADO, 1980, p.90-91).

Do ponto de vista econômico, um dos fatores que impedia a expansão da ideologia pan-americana e a hegemonia norte-americana na região eram os grandes investimentos britânicos. No período de 1885 a 1913 cerca de $60 \%$ desses investimentos dirigiam-se, especialmente, para o Brasil e a Argentina (que teve duplicado os seus empréstimos a partir de 1895), de acordo com a Tabela I.

A rivalidade com a Argentina, acabou motivando no país uma maior aproximação e aliança com o governo americano. Em 1886 o senador Frye apresenta-

\section{Tabela I}

Investimentos Britânicos na América Latina no período de 1885 a 1913.

\begin{tabular}{ccccc}
\hline Ano & $\begin{array}{c}\text { América Latina } \\
\text { (milhões de Libras) }\end{array}$ & $\begin{array}{c}\text { Brasil (milhões } \\
\text { de Libras) }\end{array}$ & Brasil (\%) & $\begin{array}{c}\text { Argentina } \\
(\%)\end{array}$ \\
\hline 1885 & 246,6 & 47,6 & 19,3 & 18,6 \\
1895 & 552,5 & 93,0 & 16,8 & 34,6 \\
1905 & 688,3 & 122,9 & 17,9 & 36,8 \\
1913 & $1.177,5$ & 254,8 & 21,6 & 40,7 \\
\hline
\end{tabular}

Tabela construída a partir de Sérgio Silva. Expansão Cafeeira e Origens da Indústria no Brasil. São Paulo, Alfa Omega, 1976, p.36-38.

va no Congresso americano um projeto para a criação da União Aduaneira Americana, sendo no ano seguinte proposto pelo presidente Cleveland o Zollverein ao Brasil. O interesse americano era penetrar o mercado brasileiro, superar a concorrência com os ingleses e dominar as relações econômicas e comerciais (BANDEIRA, 1978, p.137). 
A partir da instalação da República o novo governo, contrário ao domínio hegemônico da Inglaterra, voltava-se para os Estados Unidos, que já era o maior comprador dos produtos brasileiros desde a década de 1870. O pan-americanismo tomava corpo, apesar das manifestações nacionalistas que pregavam a expropriação das companhias estrangeiras, a luta contra o capital externo. Rui Barbosa, embora criticado pelos positivistas Miguel de Lemos e Teixeira Mendes, transpõe para a Constituição do país elementos da Constituição americana (a começar pela nova denominação de Estados Unidos do Brasil). Com a consolidação da República, ao vencer os monarquistas e as oligarquias aliadas ao capital inglês, Floriano Peixoto abre caminho para maior influência dos Estados Unidos.

A aproximação e o apoio político dos Estados Unidos ao seu governo quando da revolta da Armada em 1893, produziram dividendos econômicos. O capital americano foi favorecido nas questões tarifárias e nas concessões importantes que permitiram a ampliação de suas atividades no país (SINGER, 1975). Passada a fase dos governos militares, de Deodoro e Floriano, a ideologia do pan-americanismo retraiu, face aos novos avanços imperialistas na América Central e no Pacífico.

Em fins de 1902 a Alemanha e a Inglaterra bloqueiam a Venezuela, obrigando-a ao pagamento das dívidas atrasadas. Esse comportamento dos países europeus recebeu protestos do Ministério das Relações Exteriores do Brasil, do Barão do Rio Branco, que cobrou um posicionamento dos E.U.A. No entanto, a Inglaterra e a Alemanha já haviam consultado secretamente o Departamento de Estado americano sobre a operação, assegurando que não era sua intenção a conquista do território.

Para Bomfim, o papel de salva-guarda da Grande República não era de interesse das nações sul-americanas, pois o governo dos Estados Unidos manifestava idêntica opinião à dos europeus. Os sulamericanos também eram vistos por aqueles como "imprestáveis", "ingovernáveis" e não tinham condições de serem soberanos, devendo ser tutelados politicamente. Adequando-se ao papel de salva-guarda do hemisfério ocidental, Theodore Roosevelt, como presidente, ao mesmo tempo que pressionava a Colômbia para obter um acordo sobre a fortificação e administração americana da zona do canal, referia-se aos colombianos como sendo "aquelas criaturas desprezíveis de Bogotá", "esses corruptos idiotas e homicidas" que mereciam uma "boa lição" (LEUCHTENBERG, 1976, p.150).

$\mathrm{Na}$ sua interpretação era uma e mesma ameaça: o imperialismo europeu ou o norte-americano. Na crítica à Doutrina Monroe, afirmava:

"Proteção" já é meia conquista, e um povo ou uma nação só se pode considerar livre e soberano quando por si mesmo se garante, e é bastante forte para defender-se e bastante caracterizado e culto para não se deixar assimilar ou eliminar. As nações da América Latina não podem aceitar, contentes ou resignadas a absorção progressiva da nossa soberania por parte dos mesmos Estados Unidos (BOMFIM, 1905, p.342).

Muito embora, fossem constantes as críticas nos jornais à criação da Embaixada em Washington (1902), esse fato aproxima, ainda mais, o governo brasileiro dos Estados Unidos. O novo embaixador Joaquim Nabuco, que, no passado, durante a intervenção americana em 1893, fora um crítico feroz daquele país, passa a ser um dos mais ardorosos defensores da Doutrina Monroe (NOGUEIRA, 1984, p.202). Na carta em que agradece a Graça Aranha as felicitações pela sua nomeação, escrevia:

Ninguém é mais do que eu partidário de uma política exterior baseada na amizade íntima com os Estados Unidos. A Doutrina de Monroe impõe aos Estados Unidos uma política externa que se começa a desenhar, e, portanto, a nós todos também a nossa. Em tais condições a nossa diplomacia deve ser principalmente feita em Washington. Uma política assim valeria o maior dos exércitos e a maior das marinhas (...). Para mim a Doutrina de Monroe (...) significa que politicamente nós nos desprendemos da Europa tão completamente e definitivamente como a lua da terra. Nesse sentido é que sou Monroista (NABUCO, 1929, p.408). 
Por outro lado, desde que assume o Ministério das Relações Exteriores, Rio Branco atrai para a sua política o apoio de vários intelectuais. Além de Joaquim Nabuco, destacado para Washington, essa "elite" intelectual era formada por nomes como Alberto Torres, Rui Barbosa, Euclides da Cunha, Graça Aranha, Arthur Orlando, Araripe Jr., Oliveira Lima, Lúcio Mendonça, Lauro Muller, entre outros (SEVCENKO, 1985, p.72). No Ministério (1902 /1912), Rio Branco tinha como política associar-se aos Estados Unidos "em pé de igualdade" para ter o campo livre para exercer a hegemonia na América do Sul, e, para contrabalançar o poderio americano, unia-se ao Chile e a Argentina. Essa política pró-americana de Nabuco e Rio Branco foi decisiva para a intervenção brasileira no Acre, sem que houvesse o impedimento dos EUA.

$\mathrm{Na} 3^{\text {a }}$ Conferência pan-americana, realizada no Rio de Janeiro em 1906, em apoio àquela política, Rio Branco manifestou o desejo de incorporar uma moção de repúdio dos delegados contra a propaganda antiianque. Sua proposta, redigida por Nabuco, entretanto não foi apresentada, por faltar unanimidade entre os delegados (CALMON, 1943, p.90).

Porém, enquanto Oliveira Lima era mais cauteloso na adesão ao princípio da Doutrina Monroe, criticando os excessos de Joaquim Nabuco, Artur Orlando nesse mesmo ano, concordava com este sobre a aceitação do pan-americanismo:

Pan-americanismo, no bom sentido da palavra (...) não quer dizer dominação da América do Norte sobre a América do Sul; traduz idéia muito mais nobre e elevada, qual a de articulação das três Américas em uma vasta federação ou comunhão internacional de interesses políticos, econômicos e morais, com o fim de garantir à civilização futura seu pleno desenvolvimento, levar a expansão simultânea da economia e da justiça ao coração do mundo inteiro (CALMON, 1943, p.81-82).

Não se pode dizer também que havia nesse grupo de intelectuais e burocratas do Ministério das Relações Exteriores uma adesão permanente e total aos princípios da Doutrina Monroe. Alberto Torres, por exemplo, inicialmente, era simpático ao pan-americanismo. Colaborando com o Itamarati, no tempo do Barão do Rio Branco, manifestava-se favorável à Doutrina Monroe, por entender que algumas nações americanas, através dos princípios de 1823, estariam a "salvo" das potências européias. Defendia, mesmo como necessário, a intervenção passageira dos Estados Unidos para evitar o "anarquismo" nos países latino-americanos. Por isso, junto com Rui Barbosa, combate a Doutrina Drago. Revendo as suas posições mais tarde, em vários artigos denuncia o panamericanismo e a Doutrina Monroe, atrelando-os à política de dominação dos países latino-americanos e de hegemonia imperialista (LIMA SOBRINHO, 1968, p.434-450). O imperialismo, nesse caso, aparece criticado nos limites do liberalismo reformista, como um fenômeno que deve ser rejeitado pelos prejuízos causados ao país: a crescente desnacionalização da economia e a exploração intensiva das riquezas naturais (MARSON, 1979).

No entanto, ao contrário do que afirma J. Normano sobre o nacionalismo anti-ianque dos intelectuais latino-americanos, qualificando-o uma simples "reação psicológica" contra os Estados Unidos, caso de Rubén Dario, Calderon, Manoel Ugarte e devido a uma visão pessimista da América Latina, entre outros, a de Bunge, Ingenieros, Calderon, Bomfim, Monteiro Lobato, Blanco Fombona, Arguedas, podemos dizer que no caso do escritor sergipano há também outras razões. Nos seus escritos, não se vincula aos pessimistas, que aceitavam como fato dado a ingovernabilidade da América Latina e o seu atraso. Sua ideologia de emancipação econômica e libertação da vocação agrícola do país, aproximavam-no, algumas vezes, das teses dos industriais nacionalistas. Críticos da produção exclusiva do café para a exportação, os industrialistas, através do Manifesto da Associação Industrial (1881), redigido pelo médico e parlamentar Antonio Felício dos Santos, denunciavam o livre- 
cambismo como responsável pela dependência da nação aos interesses externos.

No eixo dessas reivindicações de uma política de defesa do sistema protecionista como sendo de "bom senso" para o governo, apelava-se para a moralização das classes pobres através do trabalho e para as imagens do Brasil como "país novo" e com um grande futuro. O exemplo era os Estados Unidos da América do Norte (MANIFESTO, 1881). Autores como Alcindo Guanabara (a quem Manoel Bomfim dedicaria em 1923 a obra Pensar e Dizer), Barata Ribeiro, Ozório de Almeida, Lauro Muller, exploravam a idéia de que a miséria do país era fruto não só de sua economia essencialmente agrícola, mas também da drenagem para fora da Nação de todas as suas riquezas. Para eles, as medidas governamentais não podiam ser prejudiciais à sociedade como um todo, como tinham sido as emissões inflacionárias da década de noventa. O governo deveria estabelecer, sobretudo, uma tarifa alfandegária protecionista, a abolição de impostos interestaduais, a melhoria dos transportes e redução dos fretes (LUZ, 1975, p.77).

Havia ainda entre os nacionalistas, uma consciência, como a manifestada por José Veríssimo, de que a política externa americana e a Doutrina Monroe estavam subordinadas aos interesses das grandes corporações econômicas e financeiras. Não tinham ilusões, como afirmava Veríssimo, sobre o que já era uma idéia corrente em parcela da intelectualidade latino-americana, quanto as reais intenções do pan-americanismo: "A América para os Americanos... do Norte" (VERÍSSIMO, apud PEREIRA, 1963, p.82). A frase também é citada em Bomfim, retomando os argumentos do escritor Quezada: "Es...una invención norte americana que, en 72 años, no ha tenido aplicación prática. La América para los americanos se dice, pero se agrega flegmáticamente del Norte....Esta és la genuina interpretación" (BOMFIM, 1905, p.13).

Nas raízes do pensamento desses intelectuais nacionalistas está presente uma forma de pensar a Amé- rica Latina. Há uma consciência latino-americana em gestação. A América Latina é percebida como o "que não é Europa”, "anglo-saxão", "norte-americano". E, esta forma de pensar, originária nos inícios do século XIX, quando intelectuais latino-americanos se opõem ao colonialismo, se explicita nesse contexto com a denúncia do imperialismo ianque (BOSI, 1981, p.5).

Por outro lado, a política econômica imperialista já se fazia presente em amplas extensões da região. $\mathrm{O}$ capitalismo alemão se apoderava das melhores terras produtoras da Guatemala e do comércio do café; as companhias americanas da produção açucareira de Cuba e o governo de Boston estendia o seu império sobre a produção de banana na América Central, em Porto Rico, Haiti, São Domingos (HALPERIN-DONGHI, 1972).

Na década de vinte o escritor socialista José Mariátegui explicava com maior clareza que a existência do pan-americanismo era algo exclusivamente diplomático. A submissão dos intelectuais e do país aos interesses do capital ianque deviam-se ao predomínio da moeda, das técnicas e das mercadorias norte-americanas. Segundo ele: “...a mais incipiente perspicácia descobre facilmente no pan-americanismo uma túnica do imperialismo norte-americano. O pan-americanismo não se manifesta como ideal natural do Continente. Manifesta-se antes, inequivocadamente como um ideal natural do Império Ianque" (BELLOTO e CORRÊA, 1982, p.131).

Por outro lado, a imagem de Bomfim sobre o imperialismo era original, apesar de suas ambigüidades. Identificava-o ao "polvo" ("polvo capital"), que se enriquecia às custas das populações atrasadas. A África serve-lhe de exemplo, para mostrar a natureza desse imperialismo.

Para se garantir, trazem governos, autoridades, leis, fuzis, canhões e soldados; o braço, o trabalhador será tirado das populações naturais; a teoria das raças inferiores justificará todas as opressões e cativeiros mais ou menos disfarçados, que nos serão impostos.

E, completava o seu pensamento sobre a opressão do trabalhador, 
Senhores do Transvaal, os ingleses reconheceram que era preciso obrigar os cafres a trabalhar para eles ingleses, nas minas. como fariam? O cafre não se preocupa de riqueza, e despreza o salário: impuseram-lhe então, um imposto de captação, pesadíssimo, e o cafre para ter a soma é obrigado a trabalhar, quando não é condenado (BOMFIM, 1905, p.352).

Assim, no âmbito das relações internacionais, a nação dominadora não vinha ocupar outras nações com um "intuito humanitário" ou com o objetivo de trazer-lhes "o bem, a civilização e a paz" (BOMFIM, 1905, p.352). Por outro lado, nem mesmo as "classes dominantes" do país seriam beneficiadas com a agressão imperialista, pois, perderiam seus privilégios. Essa sua visão, que não dava conta das relações dessa classe com a burguesia imperialista, enfatizava uma possível aliança nacional contra o invasor:

E esta desigualdade não existirá somente para os desgraçados, que serão reduzidos ao trabalho obrigatório, a reclusão por vagabundagem e desterrado de um ponto para outro do território, arrancados ao meio e aos costumes que estavam adaptados. Não; ela existirá para todos (BOMFIM, 1905, p.353).

Embora critique na sua obra $O$ Brasil Nação (1931) a colaboração de classes e o imperialismo monopolista, em face à possibilidade de uma invasão estrangeira admitia que a resistência popular acabaria unindo a todos, até mesmo "o mais desabusado comunista” (BOMFIM, 1905, p.349) que não aceitava o ideal de pátria. A rebeldia, segundo ele, fazia parte da tradição popular e ainda que a dominação se estendesse além das costas marítimas, a luta seria "feroz",

\section{Bibliografia}

BANDEIRA, Moniz. Presença dos Estados Unidos no Brasil. Dois Séculos de História. São Paulo, Civilização Brasileira, 1978. BARRETO, Lima. "Correspondência". Tomo I, 2 ed., pref. Antonio Noronha Santos. São Paulo, Brasiliense, 1961, vol.XVI. BELlOTO, Manoel e CORRÊA, Anna Maria Martinez. A Amé- "implacável", como ocorrera na resistência dos paraguaios ante "mais da metade da América do Sul", ou, dos "jagunços" no Brasil, que resistiram até à morte (BOMFIM, 1905, p.345). Retomava, desse modo, ao valorizar romanticamente a resistência e as suas formas, o velho espírito jacobino dos tempos em que (1886) fora secretário e redator do jornal jacobino República:

Será uma resistência desorganizada, muitas vezes, mas por isto mesmo permanente, irredutível, garantida pelas condições gerais de vida, mais propícia do que eram às dos portugueses e espanhóis, investidos pelas hostes de Bonaparte. A organização econômica é tão rudimentar, e a barbária é tal e o clima tão favorável, que o viver eternamente em guerrilhas parecerá uma delícia (BOMFIM, 1905, p.345, grifos nossos).

$\mathrm{Na}$ sua análise, ainda que enfatize de maneira romântica o ideal de solidariedade latino-americana e a resistência ao imperialismo, não desconhecia, por outro lado, as razões sobre a natureza do atraso do Continente. Este não era fruto de nenhum dos fatores apontados pela ideologia liberal e a imperialista: "as revoluções freqüentes", "a instabilidade dos governos", "a irregularidade do câmbio", "a falta de braços” (BOMFIM, 1905, p.19). O atraso latino-americano estava ligado ao seu passado, aos "males" implantados pelo colonialismo metropolitano e preservados pela ação conservadora das classes dirigentes. Males, que, no contexto atual, reforçam diversas representações da opinião pública européia e norte-americana sobre a América Latina como o continente da "miséria", da "fome" e da "doença" (TOURAINE, 1989, p.20).

rica Latina de Colonização Espanhola. São Paulo, HUCITEC/EDUSP, 1979. Mariátegui: Política. São Paulo, Ática, 1982.

BOMFIM, Manoel. A América Latina: males de origem. O parasitismo social e evolução. Rio de Janeiro, Paris, Garnier, s.d. (1905). 
. Lições de Pedagogia. Teoria e Prática da Educação. Rio de Janeiro, Livraria Escolar, 1915.

Noções de Psicologia. Teoria e Prática da Educação. Rio de Janeiro, Livraria Escolar, 1916.

Pensar e Dizer. Estudo do símbolo no pensamento e na linguagem. Rio de Janeiro, Casa Electros, 1923.

O Brasil na América. Caracterização da formação brasileira. Rio de Janeiro, Francisco Alves, 1929.

O Brasil na História. Deturpações das tradições, degradação política. Rio de Janeiro, Francisco Alves, 1930.

O Brasil Nação. Realidade e Soberania Brasileira. Rio de Janeiro, Francisco Alves, 1931, 2 vols.

BURNS, E. Bradford. "As relações internacionais do Brasil durante a Primeira República", in História Geral da Civilização Brasileira, tomo III. O Brasil Republicano, v.2. Sociedade e Instituições (1889-1930), 2 ed., São Paulo, DIFEL, 1978.

CALMON, Pedro. Brasil e América. História d'uma Política. Rio de Janeiro, José Olympio, 1943.

CUNHA, Euclides. Contrastes e Confrontos. São Paulo, Cultrix, 1975.

HALPERIN-DONGHI, Túlio. História Contemporânea de América Latina. 3 ed., Madrid, Alianza Ed. S.A., 1972.

LEROY-BEAULIEU, Paul. "América Latina". A Universal. Revista das Revistas, resenha da vida nacional e estrangeira. Rio de Janeiro, 20 de fevereiro de 1902, n.31, ano II.

LEUCHTENBERG, William. O Século Inacabado. A América desde 1900. Rio de Janeiro, Zahar, 1976.

LIMA, Oliveira. Obra Seleta. Rio de Janeiro, Instituto Nacional do Livro, 1971.

. Impressões da América Espanhola (1904-1906). Rio de Janeiro, José Olympio, 1953.

LIMA SOBRINHO, Barbosa. Presença de Alberto Torres (Sua vida e pensamento). Rio de Janeiro, Civilização Brasileira, 1968.

LUZ, Nícia Vilela. A Luta pela Industrialização do Brasil. São Paulo, Alfa-Omega, 1975.

MANIFESTO da Associação Industrial (1881). Apresentação Reynaldo Pessoa, in Temas de Ciências Humanas, vol.1, São Paulo, Grijalbo, 1977.

MARSON, Adalberto. A ideologia Nacionalista em Alberto Torres. São Paulo, Duas Cidades, 1979.
MARTI, José. "Vindicación de Cuba", in Retamar, Roberto F. (Seleción y prólogo). Letras Fieras. La Habana, Ed. Letras Cubanas, 1985.

NABUCO, Carolina. A Vida de Joaquim Nabuco. 2 ed., Cia Ed. Nacional, 1929.

NOGUEIRA, Marco Aurélio. As Desventuras do Liberalismo: Joaquim Nabuco, a Monarquia e a República. Rio de Janeiro, Paz e Terra, 1984.

NORMANO, J. F. A Luta pela América do Sul. São Paulo, Ed. Atlas S/A, s.d.

NOVAIS, Fernando. Estrutura e Dinâmica do Antigo Sistema Colonial (Séculos XVI e XVIII). Caderno CEBRAP, 17, 3ed, São Paulo, Brasiliense, 1977.

PEREIRA, Astrogildo. "José Veríssimo sem ilusão americana". Crítica Impura. Autores e problemas. Rio de Janeiro, Civilização Brasileira, 1963, p.82-88.

PEREYRA, Carlos. El mito Monroe. Buenos Aires, Jorge Alvarez, ed. S.A., 1969.

PERKINS, Dexter. História de la Doutrina Monroe. Buenos Aires, Ed. Universitária de Buenos Aires, 1964.

PRADO, Eduardo. A Ilusão Americana. 5ed., São Paulo, IBRASA, 1980.

SEVCENKO, Nicolau. Literatura como Missão. Tensões sociais e criação cultural na Primeira República. 2ed, São Paulo, Brasiliense, 1985.

SILVA, Sérgio. Expansão Cafeeira e Origens da Indústria no Brasil. São Paulo, Alfa Omega, 1976.

SINGER, Paul. "O Brasil no Contexto do Capitalismo Internacional 1889-1930”, in História Geral da Civilização Brasileira. Tomo III, O Brasil Republicano, vol.1, Estrutura de Poder e Economia (1889-1930). São Paulo, DIFEL, 1975, p.345-390.

SODRÉ, Nelson Werneck. O Governo Militar Secreto. Rio de Janeiro, Bertrand Brasil, 1987.

TOURAINE, Alain. Palavra e Sangue. Política e Sociedade na América Latina. São Paulo, Trajetória Cultural, Campinas, Ed. da Universidade de Campinas, 1989.

VICTOR, Nestor. "A América Latina". Os Anais. Semanário de Literatura, Arte, Ciência e Indústria. Ano II, n.51, Rio de Janeiro, 5 de outubro de 1905. 